\title{
A SNP-based phylogenetic analysis of Corynebacterium diphtheriae in Malaysia
}

\author{
Shirley Yi Fen Hii ${ }^{*}$, Norazah Ahmad ${ }^{1}$, Rohaidah Hashim', Yii Ling Liow¹, Muhammad Adib Abd Wahab \\ and Mohd Khairul Nizam Mohd Khalid²
}

\begin{abstract}
Objective: There is a lack of study in Corynebacterium diphtheriae isolates in Malaysia. The alarming surge of cases in year 2016 lead us to evaluate the local clinical C. diphtheriae strains in Malaysia. We conducted single nucleotide polymorphism phylogenetic analysis on the core and pan-genome as well as toxin and diphtheria toxin repressor (DtxR) genes of Malaysian C. diphtheriae isolates from the year 1986-2016.

Results: The comparison between core and pan-genomic comparison showed variation in the distribution of $C$. diphtheriae. The local isolates portrayed a heterogenous trait and a close relationship between Malaysia's and Belarus's, Africa's and India's strains were observed. A toxigenic C. diphtheriae clone was noted to be circulating in the Malaysian population for nearly 30 years and from our study, the non-toxigenic and toxigenic $C$. diphtheriae strains can be differentiated significantly into two large clusters, A and B respectively. Analysis against vaccine strain, PW8 portrayed that the amino acid composition of toxin and DtxR in Malaysia's local strains are well-conserved and there was no functional defect noted. Hence, the change in efficacy of the currently used toxoid vaccine is unlikely to occur.
\end{abstract}

Keywords: Diphtheria, Malaysia, Toxigenic, Pan-genome analysis, Phylogenetic tree

\section{Introduction}

Corynebacterium diphtheriae is the causative agent for diphtheria, an acute, communicable disease among children, which can be fatal. The disease is transmitted through contact with respiratory droplets from infected individuals. During the pre-immunization era, diphtheria toxin (tox) was the major cause of mortality in the infected individuals. The disease showed a tremendous reduction after the introduction of toxoid vaccine (PW8) in the twentieth century and currently remaining at less than 8000 reported cases worldwide in year 2016 [1]. The clinical presentation is generally characterized by the formation of an inflammatory pseudomembrane at the upper respiratory tract [2]. The interaction between the bacteria and its infecting phage plays an important role in the bacterial toxin acquisition. DtxR, an iron-dependent

\footnotetext{
*Correspondence: shirley@imr.gov.my

${ }^{1}$ Bacteriology Unit, Infectious Diseases Research Centre, Institute for Medical Research, Jalan Pahang, 50588 Kuala Lumpur, Wilayah Persekutuan Kuala Lumpur, Malaysia

Full list of author information is available at the end of the article
}

toxin repressor produced by $C$. diphtheriae regulates the expression of tox introduced via corynebacteriophage by repressing the transcription of tox under high iron condition and vice versa [3, 4].

In Malaysia, diphtheria toxoid vaccine is listed in the Malaysia immunization schedule and provided by the Ministry of Health Malaysia. However, not all parents bring their children for vaccination as it is not mandatory. The unvaccinated individuals would be at high risk to acquire the disease from potential diphtheria carriers. Sporadic cases were spotted over the years and recently, there was a sudden surge of diphtheria cases in year 2016, with 31 cases compared to 4, 2, 4 cases in year 2013, 2014 and 2015 respectively [5]. Our study provides the general overview of Malaysia's $C$. diphtheriae by determining the relatedness among local $C$. diphtheriae isolated within 31 years (from year 1986 to 2016) and comparing these strains with other strains worldwide using single nucleotide polymorphism (SNP) analysis. We also studied the genetic variability of tox and DtxR in these strains.

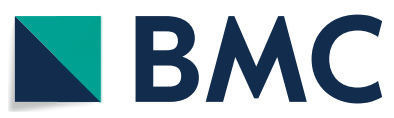

(c) The Author(s) 2018. This article is distributed under the terms of the Creative Commons Attribution 4.0 International License (http://creativecommons.org/licenses/by/4.0/), which permits unrestricted use, distribution, and reproduction in any medium, provided you give appropriate credit to the original author(s) and the source, provide a link to the Creative Commons license, and indicate if changes were made. The Creative Commons Public Domain Dedication waiver (http://creativecommons.org/ publicdomain/zero/1.0/) applies to the data made available in this article, unless otherwise stated. 


\section{Main text}

\section{Materials and methods}

A total of eighty $C$. diphtheriae isolates comprising of 58 toxigenic and 22 non-toxigenic strains from Malaysia, India, Belarus, Africa, Brazil, United Kingdom, Italy and USA were analysed in this study including 28 Malaysia's isolates (27 toxigenic and 1 non-toxigenic) which we had submitted previously to GenBank under project PRJNA345527 [6]. All the 27 toxigenic strains showed positive Elek test [7]. The other selected genomes were selected randomly from the $C$. diphtheriae strains deposited in GenBank [8-11]. All the genome data used in this study and their accession numbers were specified in Table 1 . The construction of the phylogenetic trees was done using kSNP version 3.0 [12] at k-mer $=19$ and illustrated by FigTree version 1.4.3 [13]. Two individual phylogenetic trees were constructed based on the SNPs in core genome and pan genome. For pan genome analysis, only the shared SNPs found in at least $90 \%$ of the genome were considered. The change of the SNPs is inferred by the branch length. The phylogenetic tree was analyzed at bootstrap value $>0.9$ and arranged in decreasing order. Multiple sequence alignments for tox and $D t x R$ genes were constructed and analysed by Clustal Omega [14].

\section{Results and discussion}

In this study, we used a total of 80 genomes including toxin and non-toxin bearing $C$. diphtheriae to create an overview of $C$. diphtheriae strains in Malaysia. With the advance in next generation sequencing, we applied whole genome SNP analysis in our study by comparing the SNPs in core genome and pan-genome which includes the full complement of bacterial genes: core genome and dispensable genome $[15,16]$. The relationship between specific geographical locations within Malaysia which consist of Peninsular and East Malaysia were not evaluated in the study. We assumed that there were frequent movements of the probable carriers between these two areas which might affect our analysis.

Lesser SNPs was observed in core genome $(29,184$ SNPs) compared to pan-genome (55,071 SNPs). Both core (Fig. 1) and pan-genome (Fig. 2) SNP-based phylogenetic analysis divided the $C$. diphtheriae strains into two large clusters: I, II and A, B respectively. We observed an almost equal percentage of toxigenic and non-toxigenic strains in cluster I and II using core genome phylogenetic analysis. However, in pan-genome phylogenetic analysis, the majority of the toxigenic strains were in cluster $\mathrm{B}$ (75.9\%) whilst non-toxigenic resided in cluster A (63.6\%). Further statistical analysis using Pearson's Chi square test showed that there is a significant difference between cluster $\mathrm{A}$ and $\mathrm{B}$ with $\mathrm{A}$ consisting of non-toxigenic strains and vice versa at $p=0.001$. The majority of Malaysia's toxigenic isolates $(85.2 \%)$ were clustered in B except for C110, C319, C517 and RZ358. These four isolates as well as toxigenic strains: TH510, TH1526 from India; CD1791, CD2173, CD72, CD2225, CD5052, CD4728 from Belarus; CD31A from Brazil along with NCTC13129 and NCTC5011 from United Kingdom, were scattered among the non-toxin bearing isolates. Among them, 3 out of 4 Malaysia's toxigenic isolates (C110, C319, C517), except RZ358, claded with those from Belarus and United Kingdom in cluster A. These observations showed that there is a unique and close relationship between these non-toxigenic and toxigenic strains. Therefore, there is a possibility that the tox may not be the cause of the pathogenicity which may bear to the ineffectiveness of the toxoid vaccine. The rising awareness of the other virulence factors besides toxin has brought to the investigations on iron acquisition system, resistance mechanism, and pathogenicity islands $[17,20,21]$.

The overall distribution of core genome and pangenome SNP-based phylogenetic tree was different. The pan-genome SNP analysis is able to detect slight changes in genetically-close organism especially those in the accessory genomes, therefore further discriminate the strains with similar core genome. This could be due to the regrouping of the strains as a result of the SNP changes in accessory genomes compared to the conserved core genome. A similar observation was also depicted by Sangal et al. showing discrepancy in the clustering and degree of variation using the same set of strains in core vs accessory genome and proteome analysis [17]. A marked difference was noted when a large cluster of toxigenic strains were shifted to cluster B and both BH8 and CD31A from Brazil to cluster A in pangenome SNP phylogenetic tree. The pan-genome SNP analysis has also brought Malaysia's strains: RZ632 and RZ356 to be closer to Africa's strains. It is also interesting to see that a number of recent outbreak strains from Malaysia, India and Africa in year 2016 were grouped closely to each other within cluster B. The clustering of the strains by both SNP analysis were slightly different with the core genome sequence alignment generated phylogenetic tree as reported by Hong et al. and Trost et al. $[8,20]$. The intra-clustering within a clade may not be altered when genetically distinct species is introduced. However, in our study, the introduction of Belarus strains showed a high relatedness with Malaysia's strains leading to the recalculation of the genetic difference and restructuring of the cluster.

PW8 (toxoid vaccine) is used as the reference and indicator for molecular analysis of tox and DtxR genes. All the local strains' tox gene were aligned and compared against PW8 using Clustal Omega. One or two points mutation were detected at nucleotide level in tox but the 
Table 1 Designation of the Corynebacterium diphtheriae isolate used in the analysis in this study

\begin{tabular}{|c|c|c|c|c|}
\hline No. & Culture no./collection no & Year of collection & Origin of strain & GenBank assembly id. \\
\hline 1 & C111 & 1986 & Malaysia & GCA_002115305.1 \\
\hline 2 & C110 & 1986 & Malaysia & GCA_001832975.1 \\
\hline 3 & C113 & 1986 & Malaysia & GCA_002115335.1 \\
\hline 4 & C122 & 1987 & Malaysia & GCA_001832945.1 \\
\hline 5 & C123 & 1987 & Malaysia & GCA_001832925.1 \\
\hline 6 & C198 & $\mathrm{n} / \mathrm{a}$ & Malaysia & GCA_002213115.1 \\
\hline 7 & C325 & 2003 & Malaysia & GCA_001832935.1 \\
\hline 8 & C488 & 2008 & Malaysia & GCA_001833005.2 \\
\hline 9 & C517 & 2010 & Malaysia & GCA_001833025.1 \\
\hline 10 & RZ252 & 2016 & Malaysia & GCA_001889785.1 \\
\hline 11 & RZ319 & 2016 & Malaysia & GCA_001889845.1 \\
\hline 12 & RZ356 & 2016 & Malaysia & GCA_001889775.1 \\
\hline 13 & RZ358 & 2016 & Malaysia & GCA_001889855.1 \\
\hline 14 & RZ373 & 2016 & Malaysia & GCA_001889825.1 \\
\hline 15 & RZ378 & 2016 & Malaysia & GCA_001889835.1 \\
\hline 16 & RZ379 & 2016 & Malaysia & GCA_001889765.1 \\
\hline 17 & C319 & 2001 & Malaysia & GCA_002115215.1 \\
\hline 18 & C324 & 2003 & Malaysia & GCA_002115285.1 \\
\hline 19 & C326 & 2003 & Malaysia & GCA_002213075.1 \\
\hline 20 & RZ553 & 2016 & Malaysia & GCA_002115325.1 \\
\hline 21 & RZ597 & 2016 & Malaysia & GCA_002115185.1 \\
\hline 22 & RZ600 & 2016 & Malaysia & GCA_002115155.1 \\
\hline 23 & RZ632 & 2016 & Malaysia & GCA_002115145.1 \\
\hline 24 & RZ656 & 2016 & Malaysia & GCA_002115125.1 \\
\hline 25 & RZ658 & 2016 & Malaysia & GCA_002115085.1 \\
\hline 26 & RZ659 & 2016 & Malaysia & GCA_002213145.1 \\
\hline 27 & RZ693 & 2016 & Malaysia & GCA_002115095.1 \\
\hline 28 & TH1526 & 2016 & India & GCA_001723445.1 \\
\hline 29 & TH510 & 2016 & India & GCA_001723465.1 \\
\hline 30 & TH1141 & 2016 & India & GCA_001723455.1 \\
\hline 31 & TH2031 & 2016 & India & GCA_001742095.1 \\
\hline 32 & TH1337 & 2016 & India & GCA_001742085.1 \\
\hline 33 & PW8 & 1896 & USA & CP003216.1 \\
\hline 34 & NCTC13129 & 1997 & UK & BX248353.1 \\
\hline 35 & $C 7 \beta^{\text {tox }+}$ & 1954 & - & СР003210.1 \\
\hline 36 & CDCE8392 & - & - & СР003211.1 \\
\hline 37 & CD31A & 1978 & Brazil & CP003206.1 \\
\hline 38 & CD176 & 1996 & Belarus & GCA_002203315.1 \\
\hline 39 & CD72 & 1996 & Belarus & GCA_002202335.1 \\
\hline 40 & CD847 & 1997 & Belarus & GCA_002203335.1 \\
\hline 41 & CD1360 & 1999 & Belarus & GCA_002202495.1 \\
\hline 42 & CD2929 & 2004 & Belarus & GCA_002202605.1 \\
\hline 43 & CD5052 & 2010 & Belarus & GCA_002203535.1 \\
\hline 44 & CD4568 & 2007 & Belarus & GCA_002202925.1 \\
\hline 45 & CD4728 & 2007 & Belarus & GCA_002203055.1 \\
\hline 46 & CD1791 & 2000 & Belarus & GCA_002203155.1 \\
\hline 47 & CD2173 & 2001 & Belarus & GCA_002203895.1 \\
\hline 48 & CD2225 & 2001 & Belarus & GCA_002203905.1 \\
\hline 49 & ST378-KZN-2015-45464 & 2015 & Africa & GCA_001875925.1 \\
\hline
\end{tabular}


Table 1 (continued)

\begin{tabular}{|c|c|c|c|c|}
\hline No. & Culture no./collection no & Year of collection & Origin of strain & GenBank assembly id. \\
\hline 50 & ST378-KZN-2015-45465 & 2015 & Africa & GCA_001875945.1 \\
\hline 51 & ST378-KZN-2015-45786 & 2015 & Africa & GCA_001875965.1 \\
\hline 52 & ST378-KZN-2016-48412 & 2016 & Africa & GCA_001876295.1 \\
\hline 53 & ST378-KZN-2015-45902 & 2015 & Africa & GCA_001876245.1 \\
\hline 54 & ST378-KZN-2015-45903 & 2015 & Africa & GCA_001876165.1 \\
\hline 55 & CD50 & 1996 & Belarus & GCA_002201145.1 \\
\hline 56 & CD1050 & 1998 & Belarus & GCA_002201165.1 \\
\hline 57 & NCTC5011 $1^{\#}$ & 1932 & UK & GCA_000263415.1 \\
\hline 58 & NCO3529 & 1931 & UK & GCA_000257885.1 \\
\hline 59 & VAO $1^{*}$ & 1999 & Brazil & СР003217.1 \\
\hline 60 & $C D 241^{*}$ & 1981 & Brazil & СР003207.1 \\
\hline 61 & INCA402* & 2000 & Brazil & СР003208.1 \\
\hline 62 & $\mathrm{HCO}^{*}$ & 1993 & Brazil & СР003212.1 \\
\hline 63 & $\mathrm{HCO}^{*}$ & 1999 & Brazil & СР003213.1 \\
\hline 64 & $\mathrm{HCO}^{*}$ & 2000 & Brazil & СР003214.1 \\
\hline 65 & $\mathrm{HCO}^{*}$ & 2003 & Brazil & СР003215.1 \\
\hline 66 & $\mathrm{HCO}^{*}$ & 2013 & Brazil & GCA_000953975.1 \\
\hline 67 & $B H 8^{*}$ & - & Brazil & СР003209.1 \\
\hline 68 & Aberdeen* & 2009 & UK & GCA_000455805.1 \\
\hline 69 & ISS3319* & - & Italy & СР025209.1 \\
\hline 70 & $1554060^{*}$ & 1999 & Italy & GCA_001026805.1 \\
\hline 71 & NCTC11397* & 1969 & USA & LN831026.1 \\
\hline 72 & $1554746^{*}$ & 2000 & Italy & GCA_001026845.1 \\
\hline 73 & ISS4749* & 2000 & Italy & GCA_001188005.1 \\
\hline 74 & RZ523* & 2016 & Malaysia & GCA_002115225.1 \\
\hline 75 & CD4010* & 2004 & Belarus & GCA_002202815.1 \\
\hline 76 & CD4288* & 2006 & Belarus & GCA_002203015.1 \\
\hline 77 & CD4502* & 2006 & Belarus & GCA_002203705.1 \\
\hline 78 & ST395-KZN-2015-45784* & 2015 & Africa & GCA_001876175.1 \\
\hline 79 & ST402-SA-1980-2337* & 1980 & Africa & GCA_001876285.1 \\
\hline 80 & CD4461* & 2006 & Belarus & GCA_002201075.1 \\
\hline
\end{tabular}

* Non-toxin bearing Corynebacterium diphtheriae

\# Corynebacterium diphtheriae isolate before mass vaccination

amino acid sequences were in perfect sequence identity with PW8 except for RZ319 and RZ597 which presented a non-synonymous amino acid change by the substitution of histidine to tyrosine at position 24 (H24Y) with no deleterious effect as predicted by PROVEAN $[18,19]$. This observation showed that Malaysia's strains produce single antigenic type of toxin similar to the toxoid.

Genetic variations in the composition of DtxR might influence the tox gene expression and the virulence of $C$. diphtheriae $[3,4]$. The analysis on local strains by comparing to PW8, showed that all except four $C$. diphtheriae strains, C110, C517, C319 and C113, had non-synonymous amino acid change in DtxR. Two non-synonymous SNPs: alanine to valine (A147V) and leucine to isoleucine (L214I) at position 147 and 214 respectively were located in C110, C517 and C319, all in cluster A. This observation is in concordance with a report shown by Nakao et al. who reported most amino acid substitution occurs in the carboxyl-terminal half of $D t x R$ and both the amino acid substitution, A147 and L214I were observed in Russia and Ukraine strains [3]. However, a different observation in our isolate was the amino acid substitution at position 150, changing threonine to asparagine (T150N) of C113. However, all of them were predicted to be neutral by PROVEAN $[18,19]$.

Our analysis provides a general overview on the Malaysia's $C$. diphtheriae isolates and the difference in genetic relatedness caused by the accessory genomes at a glance. Pan-genome SNP analysis allows a more rapid and efficient genetic relatedness observation using SNP variation 


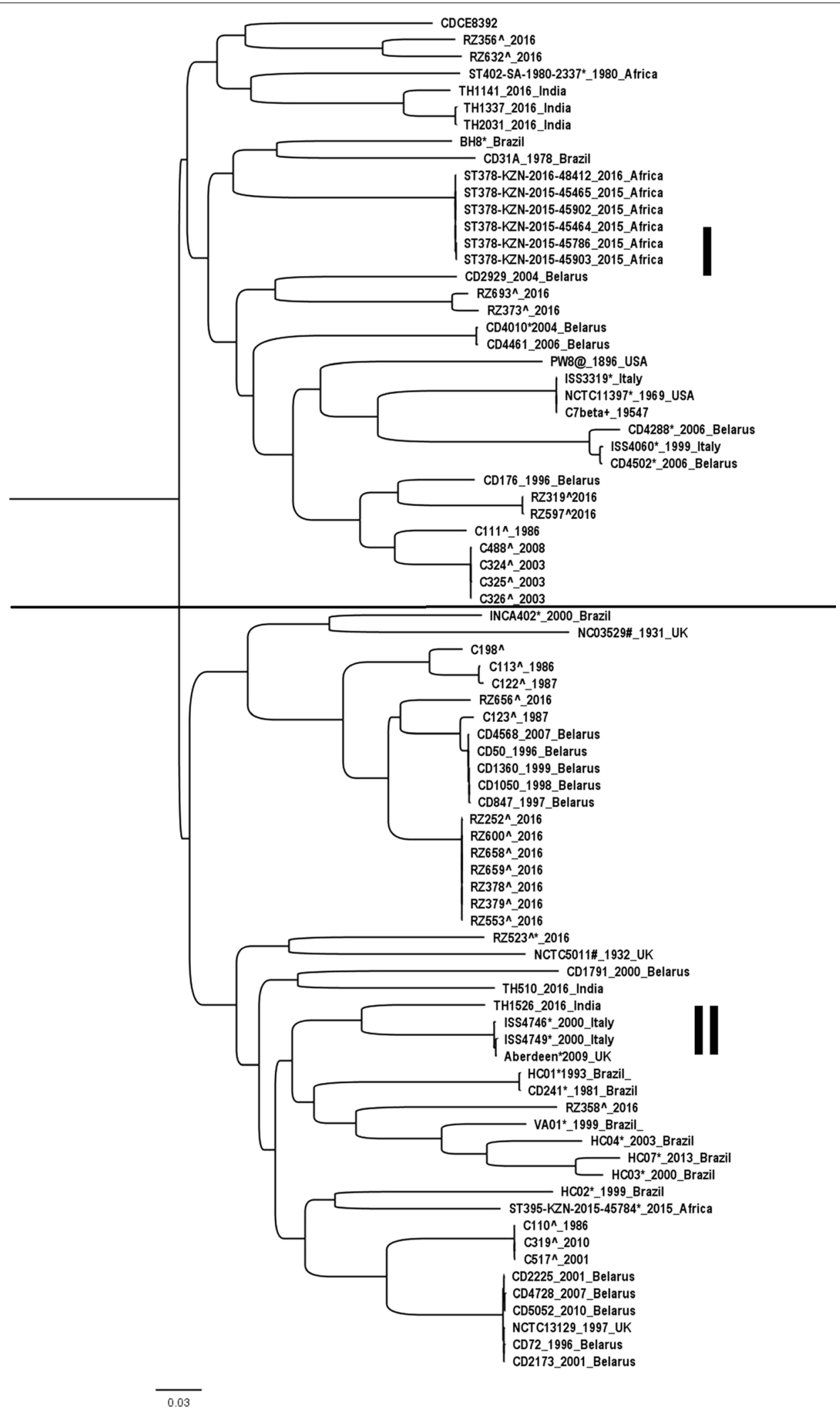

Fig. 1 Core genome SNP-based phylogenetic tree analysis of 80 Corynebacterium diphtheriae strains grouped in cluster I and II. The SNPs is only considered if there is at least $90 \%$ of the genome has the nucleotide change at the position. $\wedge$ and ${ }^{*}$ refer to Malaysia's and non-toxin bearing isolate, respectively 


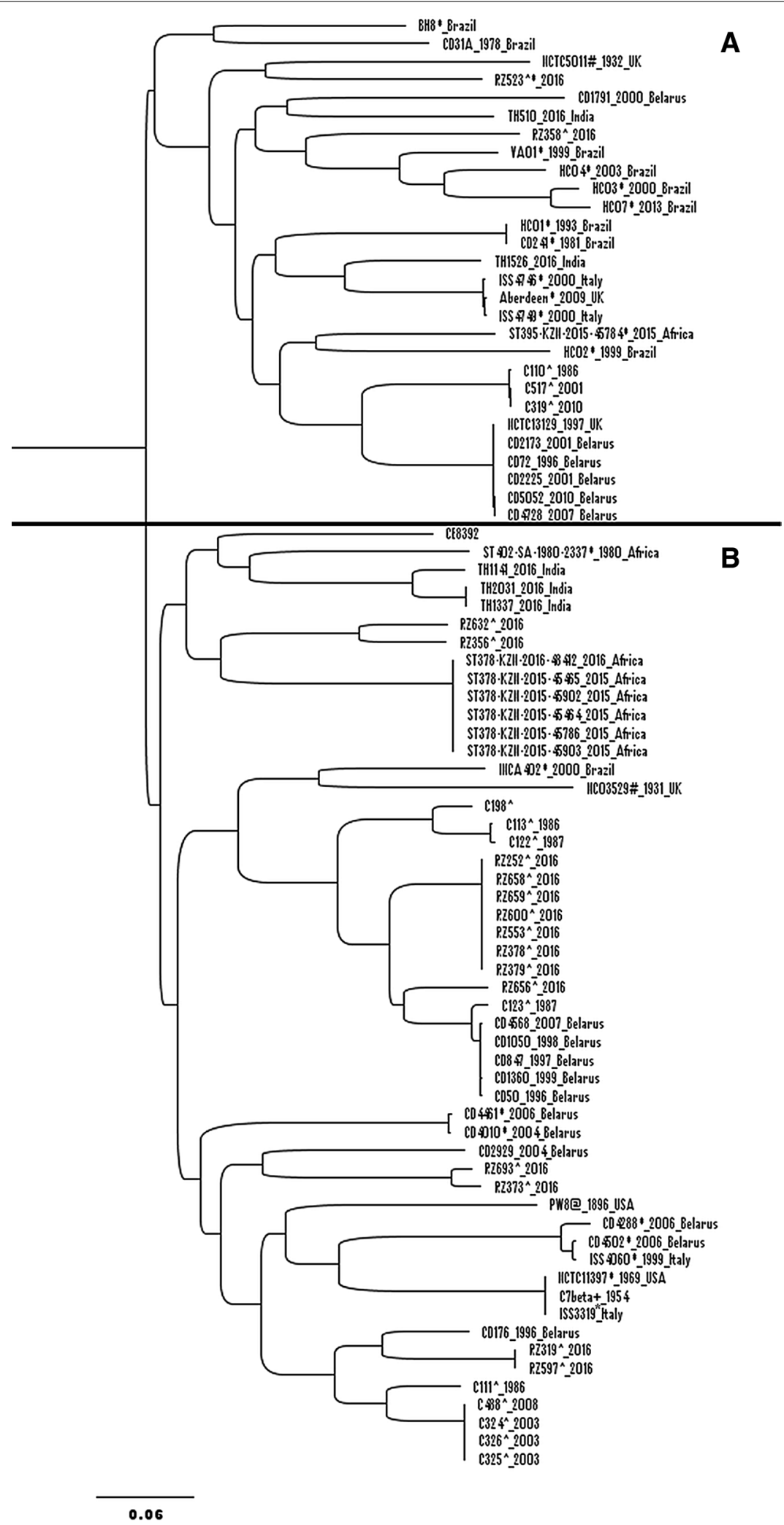

Fig. 2 Pan-genome SNP-based phylogenetic tree analysis of 80 Corynebacterium diphtheriae strains grouped in cluster A and B. The SNPs is only considered if there is at least $90 \%$ of the genome has the nucleotide change at the position. $\wedge$ and * refer to Malaysia's and non-toxin bearing isolate, respectively 
especially in outbreak study to discriminate variations in core genome and accessory genome between genetically similar species $[15,16]$. A further insight into the variability in the accessory genome between the closely related toxigenic and non-toxigenic local strains, for instance, RZ358, will be required to understand the acquired pathogenicity other than toxin such as the presence of functional genomic islands [17, 20,21]. Our current analysis has significantly divided the toxigenic and non-toxigenic strain into two clusters, focusing mainly on local isolates. The observation might differ if more toxin-bearing clones with non-toxin related pathogenicity were introduced in the future.

In conclusion, over the years, sporadic diphtheria cases in Malaysia were shown to bear diverse strains. Based on the pan-genome SNP analysis, it is possible that the C. diphtheriae strains isolated in Malaysia could be of Belarus, Africa and India origin or vice versa based on the shared SNPs. However, the majority of the strains isolated in the year 2016 outbreak were clustered with strains isolated from as early as year 1986 indicating the presence of a persistent local strain in the population for decades. The non-toxigenic and toxigenic strains can also be clustered in A and B with regards to the toxin status. All the Malaysia clinical isolates produced single antigenic type of diphtheria toxin, similar to PW8. Given the well-conserved amino acid composition of toxin and DtxR of these local isolates compared to PW8, the alteration in the efficacy of the currently used toxoid vaccine would be unlikely.

\section{Limitations}

The investigation on the specific type of accessory genome would be useful to understand the connection between toxigenic and non-toxigenic Corynebacterium diphtheriae strains in Malaysia. Most of the local C. diphtheriae isolated are toxigenic strains and only one non-toxigenic strain is available for analysis.

\section{Abbreviations \\ C. diphtheriae: Corynebacterium diphtheriae; DtxR: diphtheria toxin repressor; Tox: toxin gene; SNP: single nucleotide polymorphism.}

\section{Authors' contributions}

SYFH drafted the manuscript. NA designed the experiment and critical appraisal of the manuscript. $\mathrm{RH}$, YLL collected the isolates and conducted the toxin PCR and Elek's test of Corynebacterium diphtheriae. YLL, MAAW and SYFH carried out the whole genome sequencing experiment. SYFH, MKNMK, MAAW performed the data analysis and interpretation. All authors read and approved the final manuscript.

\footnotetext{
Author details

${ }^{1}$ Bacteriology Unit, Infectious Diseases Research Centre, Institute for Medical Research, Jalan Pahang, 50588 Kuala Lumpur, Wilayah Persekutuan Kuala Lumpur, Malaysia. ${ }^{2}$ Molecular Diagnostics and Protein Unit, Specialised Diagnostics Centre, Institute for Medical Research, Jalan Pahang, Kuala Lumpur 50588, Wilayah Persekutuan Kuala Lumpur, Malaysia.
}

\section{Acknowledgements}

The authors would like to thank the Director General of Health, Ministry of Health Malaysia and Director of the Institute for Medical Research for permis sion and support to publish this article. We would also like to acknowledge the help of Mr. Kee Chee Cheong, from Epidemiology and Biostatistics Unit, Institute for Medical Research, for the statistical analysis performed in this study.

\section{Competing interests}

The authors declare that they have no competing interests.

Availability of data and materials

All the data analyzed in this study is included in this article.

Consent for publication

Not applicable.

\section{Ethical approval and consent to participate}

This work does not involve the use of human participants and related samples, therefore granted an exemption by Malaysia Medical Research and Ethics Committee (MREC).

\section{Funding source}

This project under NMRR id: 16-1421-32070 (JPP-IMR: 16-056) is supported by the Ministry of Health Malaysia's Grant.

\section{Publisher's Note}

Springer Nature remains neutral with regard to jurisdictional claims in published maps and institutional affiliations.

Received: 27 September 2018 Accepted: 17 October 2018

Published online: 25 October 2018

\section{References}

1. World Health Organization. Diphtheria reported cases. Last update: 6 September 2017. http://apps.who.int/immunization_monitoring/globa Isummary/timeseries/tsincidencediphtheria.html. Accessed 29 Nov 2017.

2. Hadfield TL, McEvoy P, Polotsky Y, Tzinserling VA, Yakovlev AA. The pathology of diphtheria. J Infect Dis. 2000;181:116-20.

3. Nakao H, Mazurova IK, Glushkevich T, Popovic T. Analysis of heterogeneity of Corynebacterium diphtheriae toxin gene, tox, and its regulatory element, DtxR by direct sequencing. Res Microbial. 1997;148:45-54.

4. Boyd JM, Hall KC, Murphy JR. DNA sequences and characterization of DtxR alleles from Corynebacterium diphtheriae PW8(-), 1030(-), and C7hm723(-). J Bacteriol. 1992;174(4):1268-72.

5. World Health Organisation. Diphtheria global annual reported cases and DTP3 coverage, 1980-2016. Data as of 19 July 2017. http://www. who.int/immunization/monitoring_surveillance/burden/diphtheria/en/. Accessed 29 Nov 2017.

6. Ahmad N, Hii SYF, Mohd Khalid MKN, Abd Wahab MA, Hashim R, Tang SN, Liow YL, Hamzah N, Dahalan NA, Seradja V. First draft genome sequences of malaysian clinical isolates of Corynebacterium diphtheriae. Genome Announc. 2017:5(9):e01670-716.

7. Engler KH, Glushkevich T, Mazurova IK, George RC, Efstratiou A. A modified Elek test for detection of toxigenic corynebacteria in the diagnostic laboratory. J Clin Microbiol. 1997;35(2):495-8.

8. Hong KW, Asmah Hani AW, Nurul Aina Murni CA, Pusparani RR, Chong CK, Verasahib K, YusoffWN, Noordin NM, Tee KK, Yin WF, Yu CY, Ang GY, Chan KG. Comparative genomic and phylogenetic analysis of a toxigenic clinical isolate of Corynebacterium diphtheriae strain B-D-16-78 from Malaysia. Infect Genet Evol. 2017;54:263-70.

9. Plessis MD, Wolter N, Allam M, Gouveia LD, Moosa F, Ntshoe G, Blumberg L, Cohen C, Smith M, Mutevedzi P, Thomas J, Horne V, Moodley P, Archary M, Mahabeer Y, Mahomed S, Kuhn W, Mlisana K, McCarthy K, Gottberg AV. Molecular characterization of Corynebacterium diphtheriae outbreak isolates, South Africa, March-June 2015. Emerg Infect Dis. 2017;23(8):1308-15 
10. Veeraraghavan B, Anandan S, Sekar SKR, Gopi R, Ragupathi NKD, Ramesh S, Verghese P, Korulla S, Mathai S, Sangal L, Joshi S. First report on the draft genome sequences of Corynebacterium diphtheriae Isolates from India. Genome Announc. 2016;4(6):e01316-416.

11. Grosse-Kock S, Kolodkina V, Schwalbe EC, Burkovski JBA, Hoskisson PA, Brisse B, Smith D, Sutcliffe IC, Titov L, Sangal V. Genomic analysis of endemic clones of toxigenic and non-toxigenic Corynebacterium diphtheriae in Belarus during and after the major epidemic in 1990s. BMC Genomics. 2017:18:873.

12. Gardner SN, Hall BG. When whole-genome alignments just won't work; kSNP V2 software for alignment-free SNP discovery and phylogenetics of hundreds of microbial genomes. PLoS ONE. 2013;8(12):e81760.

13. Figtree v1.4.3. http://tree.bio.ed.ac.uk/software/figtree/.

14. Sievers F, Wilm A, Dineen DG, Bibson TJ, Karplus K, Li W, McWilliam H, Remmert M, Söding J, Thompson JD, Higgins DG. Fast, scalable generation of high-quality protein multiple sequence alignments using Clustal Omega. Mol Syst Biol. 2011;7:539.

15. Medini D, Donati C, Tettelin H, Masignani V, Rappuoli R. The microbial pan-genome. Curr Opin Genet Dev. 2005;15(6):589-94.

16. Dangel A, Berger A, Konrad R, Bischoff H, Sing A. Geographically diverse clusters of nontoxigenic Corynebacterium diphtheriae infection, Germany, 2016-2017. Emerg Infect Dis. 2018;24:7.

17. Sangal V, Blom J, Sutcliffe IC, Hunolstein CV, Burkovski A, Hokisson PA. Adherence and invasive properties of Corynebacterium diphtheriae strains correlates with the predicted membrane-associated and secreted proteome. BMC Genomics. 2015;16:765.

18. Ng PC, Henikoff S. Predicting the effects of amino acid substitutions on protein function. Annu Rev Genomics Hum Genet. 2006;7:61-80.

19. Choi Y, Sims GE, Murphy S, Miller JR, Chan AP. Predicting the functional effect of amino acid substitutions and indels. PLOS ONE. 2012;7(10):e46688.

20. Trost E, Blom J, Soares SDC, Huang $\|_{H}$, Al-Dilaimi A, Schröder J, Jaenicke S, Dorella FA, Rocha FS, Miyoshi A, Azevedo V, Schneider MP, Silva A, Camello TC, Sabbadini PC, Santos CS, Santos LS, Hirata R Jr, MattosGuaraldi AL, Efstratiou A, Schmitt MP, Hung TT, Tauch A. Pangenomic study of Corynebacterium diphtheriae that provides insights into the genomic diversity of pathogenic isolates from cases of classical diphtheria, endocarditis and pneumonia. J Bacteriol. 2012;194(12):3199-215.

21. Cerdeño-Tárraga AM, Efstratiou A, Dover LG, Holden MTG, Pallen M, Bentley SD, Besra GS, Churcher C, James KD, Zoysa AD, Chillingworth T, Cronin A, Dowd L, Feltwell T, Hamlin N, Holroyd S, Jagels K, Moule S, Quail MA, Rabbinowitsch A, Rutherford KM, Thomson NR, Unwin L, Whitehead S, Barrell BG, Parkhill J. The complete genome sequence and analysis of Corynebacterium diphtheriae NCTC13129. Nucleic Acids Res. 2003;31(22):6516-23.
Ready to submit your research? Choose BMC and benefit from:

- fast, convenient online submission

- thorough peer review by experienced researchers in your field

- rapid publication on acceptance

- support for research data, including large and complex data types

- gold Open Access which fosters wider collaboration and increased citations

- maximum visibility for your research: over 100M website views per year

At BMC, research is always in progress.

Learn more biomedcentral.com/submissions 